\title{
Revisiting Bromo-Hexitols as a Novel Class of Microenvironment-Activated Prodrugs for Cancer Therapy
}

Henrik Johansson, ${ }^{1, \#}$ Omar Hussain, ${ }^{2, \#}$ Simon J. Allison, ${ }^{2}$ Tony V. Robinson, ${ }^{1}$ Roger M. Phillips, $2 ;+* *$ Daniel Sejer Pedersen ${ }^{1 ;+* *}$

${ }^{1}$ Department of Drug Design and Pharmacology, Faculty of Health and Medical Science, University of Copenhagen, Jagtvej 162, 2100 Copenhagen, Denmark

${ }^{2}$ School of Applied Sciences, University of Huddersfield, Huddersfield HD1 3DH, United Kingdom

\# These authors contributed equally

$\$$ These authors contributed equally as principal investigators

* Corresponding authors: RMP (pharmacology) R.M.Phillips@ hud.ac.uk. DSP (chemistry) daniel.pedersen@sund.ku.dk.

\begin{abstract}
Bromo-hexitols represent a potent class of DNA-alkylating carbohydrate chemotherapeutics that has been largely ignored over the last decades due to safety concerns. The limited structure-activity relationship data available reveals significant changes in cytotoxicity with even subtle changes in stereochemistry. However, no attempts have been made to improve the therapeutic window by rational drug design or by using a pro-drug approach to exploit differences in tumour physiology compared to healthy tissue, such as acidic extracellular $\mathrm{pH}$ and hypoxia. Herein, we report the photochemical synthesis of highly substituted endoperoxides as key precursors for dibromo-hexitol derivatives and investigate their use as microenvironment-activated prodrugs for targeting cancer cells. One endoperoxide was
\end{abstract}


identified to have a marked increased activity under hypoxic and low $\mathrm{pH}$ conditions, indicating that endoperoxides may serve as microenvironment-activated prodrugs.

\section{INTRODUCTION}

Treosulfan (1), dibromomannitol (2, DBM) and dibromogalactitol (3, DBG) belong to a class of alkylating carbohydrate chemotherapeutics that have been known for over 40 years (Figure 1). ${ }^{[1]}$ This family of chemotherapeutics has been demonstrated to undergo in vivo transformation to generate reactive species, including mono- and bis-epoxides (e.g. conversion of $\mathbf{3}$ to $\mathbf{4}$, Figure 1 ), ${ }^{[2]}$ that primarily alkylate DNA at guanine-N7, but also histones and nuclear proteins to some extent. ${ }^{[3]}$ Despite displaying interesting and potentially useful properties for the treatment of various cancers this family of compounds is no longer undergoing clinical evaluation due to severe side effects and because no clear advantage could be demonstrated over existing therapies. ${ }^{[4]}$ These compounds are nevertheless potent cytotoxic agents and the challenge is to develop derivatives with a greater therapeutic index.<smiles>COC[C@H](O)[C@H](O)COC</smiles>

Treosulfan<smiles>OC([C@H](O)CBr)[C@H](O)CBr</smiles>

2

Dibromomannitol (DBM)<smiles>OC(C1COC1)[C@@H](O)[C@@H](O)C1(Br)CC[C@@H]1CBr</smiles>

3<smiles>OC([C@H](O)[C@H]1CO1)[C@H]1CO1</smiles>

4

Dibromogalactitol (DBG) Dianhydrogalactitol (DAG)

Figure 1. Three known DNA-alkylating chemotherapeutics: treosulfan (1), dibromomannitol (2, DBM) and dibromogalactitol (3, DBG). The cytotoxic DNA alkylating agents (e.g. 4, DAG) are formed in vivo from the dibromohexitol prodrug (e.g. 3) as illustrated. The reactive alkylating sites are highlighted with red circles. ${ }^{[3 e]}$ 
Unlike other classes of DNA-alkylating chemotherapeutics, there have only been modest attempts of exploring analogues to reduce the toxicity of dibromohexitols, such as the synthesis of other di-halogen or di-O-methane sulfonyl derivatives, as well as acetylated analogues. $^{[5]}$ Interestingly, for the known dichloro, -bromo and -iodo carbohydrates the cytotoxic activity varies considerably between structural isomers (e.g. 2 vs. 3). ${ }^{[4,5 c, 6]}$ Thus, even subtle changes in stereochemistry can alter the cytotoxic properties of the compounds, yet no attempt at exploring the structure-activity relationships has been reported. Moreover, no attempts at synthesising novel bromohexitols bearing substituents to their backbone or developing prodrugs that may display selectivity towards for example hypoxic and acidic tumours have been reported.

Endoperoxides (e.g. 5, Figure 2) are a useful class of starting materials for the synthesis of a wide range of molecules that are otherwise difficult to synthesise. ${ }^{[7]}$ As previously reported by us and others, endoperoxides are particularly useful in the synthesis of amino acids ${ }^{[8]}$ and carbohydrates. $^{[9]}$ During previous work ${ }^{[9 \mathrm{~d}, 9 \mathrm{e}]}$ on carbohydrate synthesis it came to our attention that the endoperoxide chemistry developed by us might furnish a concise route to a new series of substituted bromohexitols (Figure 3). In addition, we hypothesised that the bromo-endoperoxide intermediates could represent a novel class of hypoxia activated prodrugs (HAPs) ${ }^{[10]}$ based on the reductively labile endoperoxide linkage.

Hypoxia is a physiological characteristic of cancer cells arising from a poor and inefficient vascular supply leading to regions of tumours that are poorly perfused with blood. ${ }^{[11]}$ Taking advantage of the unique acidic and reductive microenvironment, drugs can be attached to a linker that is cleaved under acidic conditions or by one-electron reduction by ubiquitous cellular reductases, such as NADPH cytochrome $\mathrm{P} 450$ reductase ${ }^{[12]}$ or by engaging glutathione $(\mathrm{GSH})$ to release the cytotoxic agent. ${ }^{[12 a, 13]}$ Due to the susceptibility of the endoperoxide linkage to be cleaved under reductive conditions, we believed that it might be 
cleaved selectively under hypoxic conditions, thus providing access to a new class of hypoxia targeting cancer agents (Figure 2).

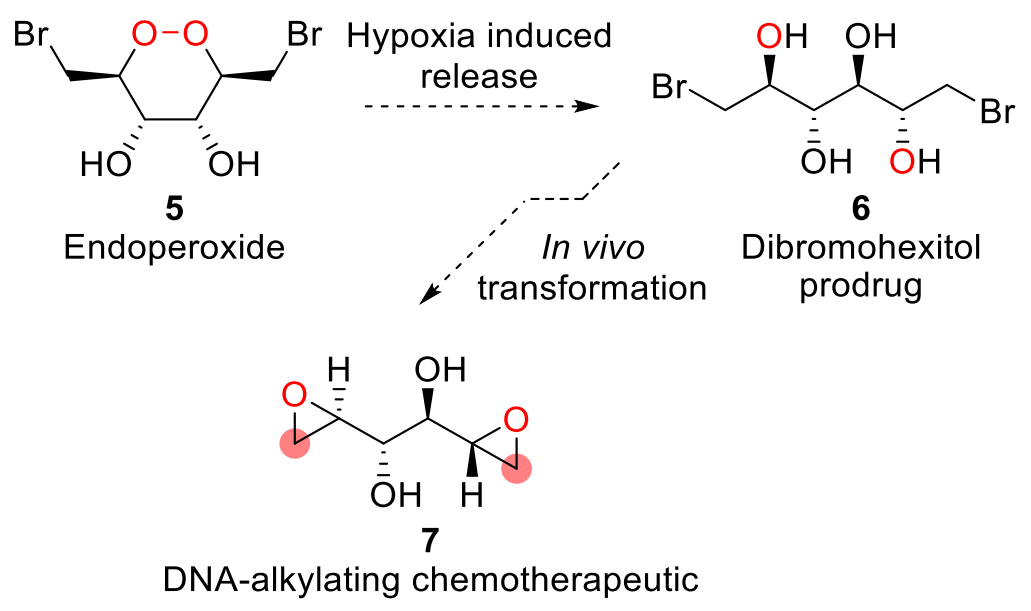

Figure 2. Hypothesised hypoxia induced reduction of endoperoxide $\mathbf{5}$ to release dibromohexitol prodrug $\mathbf{6}$, followed by formation of the cytotoxic agent 7 . The reactive DNA-alkylating sites are highlighted with red circles.

In addition to hypoxia, other physiological parameters change within these poorly perfused regions including a reduction in extracellular $\mathrm{pH}(\mathrm{pHe}) .{ }^{[14]}$ Extracellular $\mathrm{pH}$ in tumour tissues are generally more acidic $(0.5-1.0 \mathrm{pH}$ units lower) than normal tissues where intracellular $\mathrm{pH}$ is generally maintained at $7.4 \cdot{ }^{[15]}$ Thus, in addition to evaluating the endoperoxide linkage as a hypoxia trigger we decided to synthesise ligands that also incorporate acid sensitive acetal groups that potentially could serve as handles for further scaffold elaboration $e$.g. attachment of cancer targeting biomolecules (Figure 3). Lastly, we sought to explore the synthetic utility of endoperoxide intermediates for alkene functionalisation (e.g. through epoxide or bromohydrin formation). In this initial report, we describe i) the synthesis and functionalisation of substituted dibromo-endoperoxides, ii) the application of dibromoendoperoxides for the synthesis and structure-activity relationship evaluation of novel 
dibromo-hexitols, and iii) the first evaluation of dibromo-endoperoxide derivatives as microenvironment-activated prodrugs for selective targeting of cancer cells.

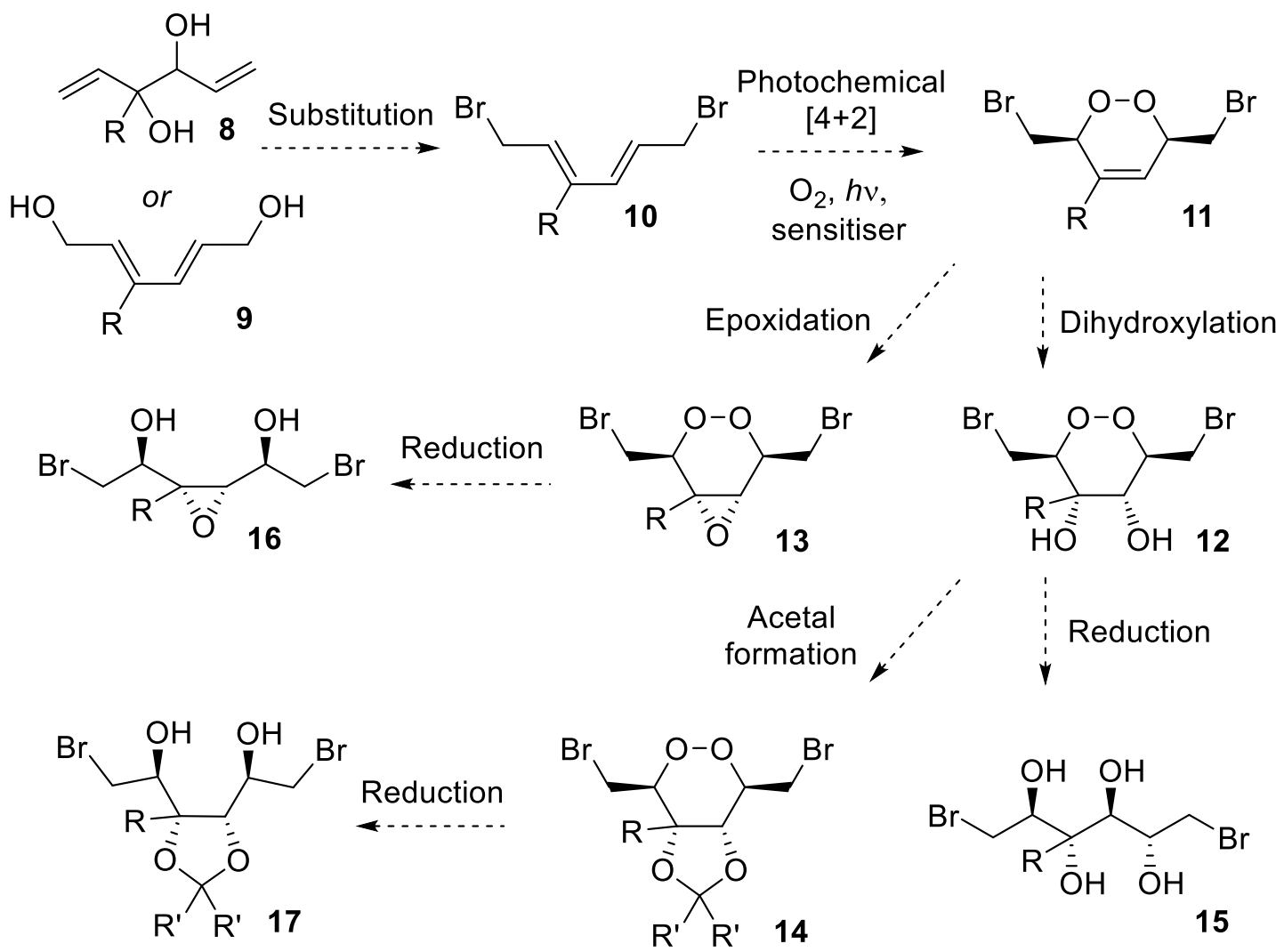

Figure 3. The outlined synthetic approach identified endoperoxides $\mathbf{1 1}$ as key intermediates for the generation of oxidised (12 and 13) and acetal derivatised (14) endoperoxides, as well as a range of substituted dibromohexitol derivatives 15-17 through chemical reduction. Endoperoxides 11 are synthesised by a photochemical [4+2]-cycloaddition between singlet oxygen and substituted bromo-dienes 10, that can be obtained by nucleophilic substitutions of various bis-allylic alcohol precursors.

\section{RESULTS \& DISCUSSION}

\section{Chemistry: Endoperoxide synthesis}

We first set out to synthesise the dibromodienes to be used in the photochemical [4+2]cycloaddition reaction. At first unsubstituted dibromodiene 19 was synthesised from the 
corresponding diol by $\mathrm{S}_{\mathrm{N}} 2$ substitution using $\mathrm{PBr}_{3}$, but we soon discovered that the yields could be significantly increased when applying $S_{N} 2$ ' substitution to hexa-1,5-diene-3,4-diol 18 with $\mathrm{CuCl}$ in aqueous $\mathrm{HBr}$ (Scheme $1 \mathrm{~A}) .{ }^{[16]}$ With a robust synthesis route to $\mathbf{1 9}$ in hand we decided to explore the analogous synthesis of substituted dibromodienes $\mathbf{2 2}$ and $\mathbf{2 6}$. Diacetal 20 was treated with vinyl magnesium bromide at low temperature to give diol $\mathbf{2 1}$, but the following substitution failed to yield any of the desired dibromodiene 22 (Figure 1B). Similarly, commercially available ketone $\mathbf{2 3}$ was treated with an excess of vinyl magnesium bromide over two steps to produce diol $\mathbf{2 5}$, but yet again we failed to produce the desired dibromodiene product $\mathbf{2 6}$.

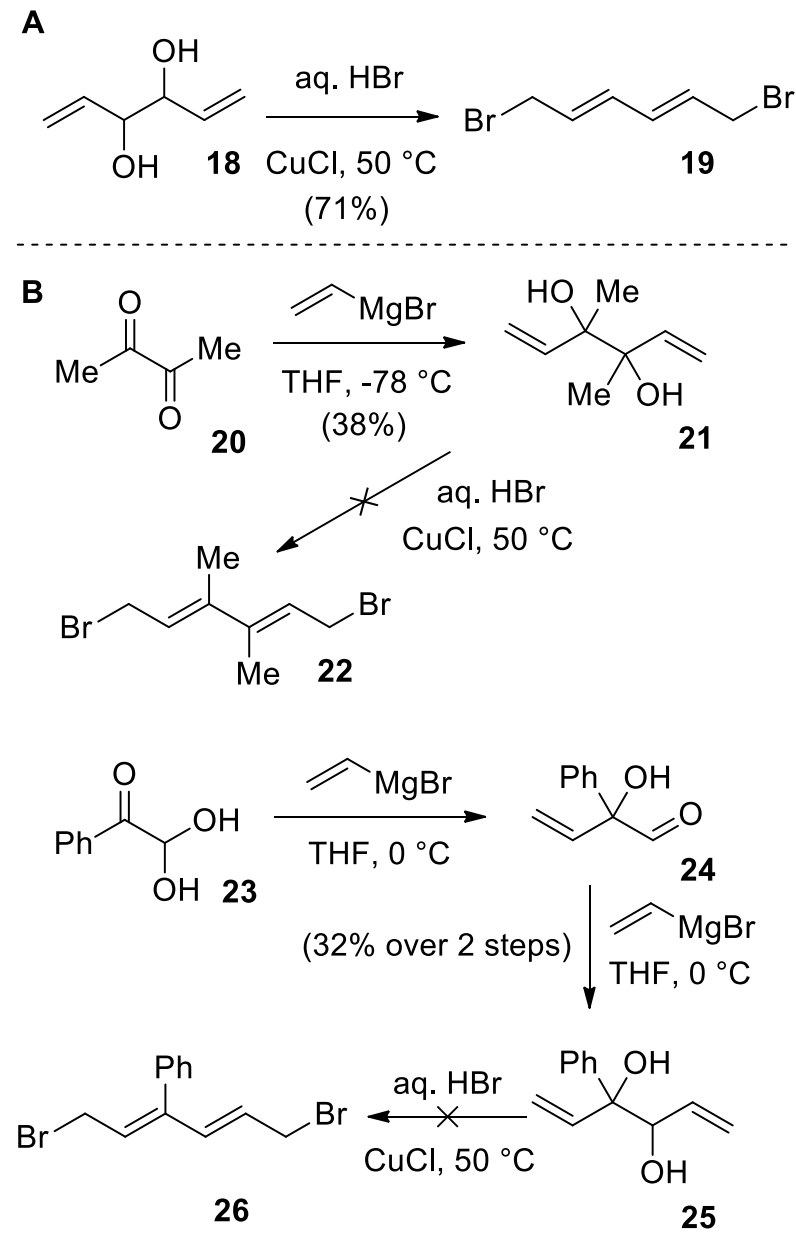


Scheme 1. A) Synthesis of dibromodiene 19 from diol 18 using aqueous $\mathrm{HBr}$ and $\mathrm{CuCl}$. B) Applying the same conditions on diols $\mathbf{2 1}$ and $\mathbf{2 5}$ failed to produce the desired dimethyl- or phenyl-substituted dibromodienes 22 and 26, respectively.

Following the unsuccessful synthesis of substituted dibromodienes via $\mathrm{S}_{\mathrm{N}} 2$ ' substitution reactions we decided to pursue the synthesis of methyl-substituted dibromodiene $\mathbf{3 4}$ by HWE/Wittig chemistry (Scheme 2). To this end, phosphonate 27 was deprotonated using potassium tert-butoxide and treated with aldehyde $\mathbf{2 8}$ to obtain a 1:1 mixture of E/Z isomers of alkene 29. In parallel, bromoacetate $\mathbf{3 0}$ was treated with triphenylphosphine to yield phosphonium bromide 31, which in turn was used in a Wittig reaction with ketone 29 to produce diene 32 as a mixture of two isomers (0.6:1 ratio). However, reducing both carboxylic esters in 32 simultaneously, using $\mathrm{LiAlH}_{4}$ in $\mathrm{THF}$ at $-78{ }^{\circ} \mathrm{C}$ or $\mathrm{NaBH}_{4}$ and $\mathrm{LiCl}$ in THF at $0{ }^{\circ} \mathrm{C}$ returned only complex reaction mixtures. Eventually 32 was reduced to the corresponding diol with diisobutylaluminium hydride (DIBAL-H) at low temperature (Scheme 2). Some variations in yields were observed for this transformation, most likely due to variations in moisture control which would affect the integrity of the reducing agent, and the laborious work-up procedure to remove aluminium contaminants. The Fieser protocol ${ }^{[17]}$ using $\mathrm{NaOH}$ and $\mathrm{MgSO}_{4}$ was generally successful in removing aluminium side products before chromatographic purification. In this manner, gram quantities of diol $\mathbf{3 3}$ were obtained. Unfortunately, when diol $\mathbf{3 3}$ was treated with $\mathrm{HBr}$ and $\mathrm{CuCl}$ none of the desired dibromodiene $\mathbf{3 4}$ was isolated. However, the synthesis of dibromodiene $\mathbf{3 4}$ was successful when using $\mathrm{PBr}_{3}$ in anhydrous diethyl ether. 


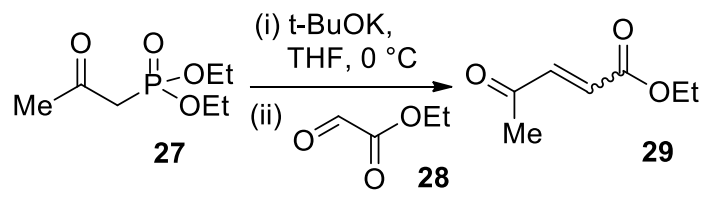

$(75 \%)$

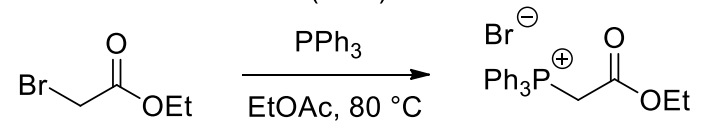

$30 \quad(95 \%)$

31

(i) t-BuOK,

PhMe, $0{ }^{\circ} \mathrm{C} \quad(50 \%)$

(ii) $29,90^{\circ} \mathrm{C}$

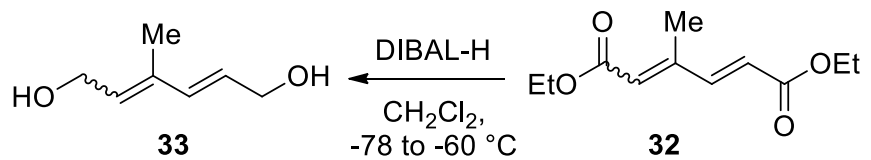

33

$(79 \%)$

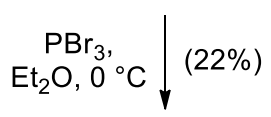

32<smiles>CC(C=CCBr)=CCBr</smiles>

34

Scheme 2. Synthesis of diol $\mathbf{3 3}$ using HWE/Wittig chemistry and its subsequent conversion to methyl-substituted dibromodiene 34. DIBAL-H = Diisobutylaluminium hydride.

With dibromodienes 19 and 34 in hand, we turned our attention to the photochemical [4+2]cycloaddition reaction between a diene and singlet oxygen generated in the presence of the photosensitiser rose bengal or tetraphenylporphyrin (TPP). The cycloaddition reactions were carried out in a cooled immersion well glass photoreactor which had been fitted with a sintered glass filter gas inlet and three white light $100 \mathrm{~W}$ halogen bulbs (Supplementary Figure S1). ${ }^{[9 a]}$ The reactor was charged with 19 or 34 and the photosynthesiser rose bengal but in both cases this consistently resulted in multiple products, sluggish reactions and poor yields. However, when the reactions were repeated with the photosensitiser TPP the desired endoperoxides $\mathbf{3 5}$ and $\mathbf{3 6}$ were obtained, albeit the reactions were slow and required several additions of TPP during the course of the reaction (Scheme 3). Dihydroxylation of endoperoxides $\mathbf{3 5}$ and $\mathbf{3 6}$ using osmium tetraoxide installed the central hydroxyl groups in a stereospecific manner anti to the alkyl substituents, to give diols $\mathbf{3 7}$ and $\mathbf{3 8}$ in high yields. 
Diols 37 and 38 were acetal-protected using 2,2-DMP to give 39 and $\mathbf{4 0}$. Tetraol 41 (dibromoallitol) was obtained by reducing the endoperoxide-linkage in $\mathbf{3 7}$ with zinc dust in acetic acid. Unfortunately, when the same conditions were applied to methyl-substituted endoperoxide $\mathbf{3 8}$ the crude product proved very difficult to purify. Thus, tetraol $\mathbf{4 2}$ was only isolated in $\sim 80 \%$ purity $\left({ }^{1} \mathrm{H}\right.$ NMR) and consequently was not included in the pharmacological characterisation.<smiles>[R]C(C=CCF)=CCBr</smiles>

$19 \mathrm{R}=\mathrm{H}$

$34 \mathrm{R}=\mathrm{Me}$

TPP, $\mathrm{O}_{2} \downarrow \mathrm{CH}_{2} \mathrm{Cl}_{2}$

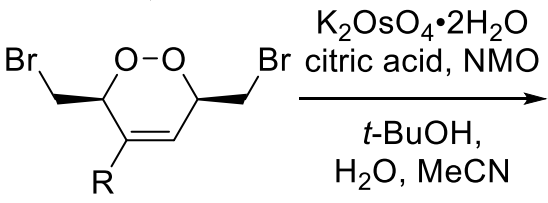

$35 \mathrm{R}=\mathrm{H}(28 \%)$

$36 \mathrm{R}=\mathrm{Me}(19 \%)$<smiles>[R2][C@@](O)([C@@H](O)[C@@H](O)CBr)[C@@H](O)CBr</smiles>

$41 \mathrm{R}=\mathrm{H}(23 \%)$

$42 \mathrm{R}=\mathrm{Me}$ (n.p.)

$\mathrm{Zn} \uparrow \mathrm{AcOH}$

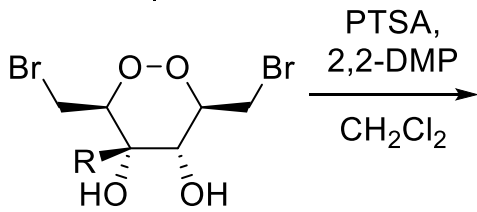

$37 \mathrm{R}=\mathrm{H}(85 \%)$

$38 \mathrm{R}=\mathrm{Me}(79 \%)$

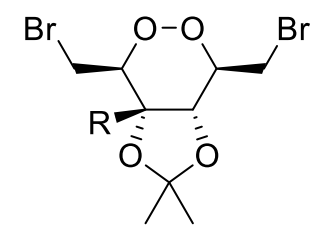

$39 \mathrm{R}=\mathrm{H}(90 \%)$

$40 \mathrm{R}=\mathrm{Me}(61 \%)$

Scheme 3. Synthesis of key endoperoxide intermediates 35 and 36 from dienes 19 (E,E isomer) and $\mathbf{3 4}$ (mix of $E, E$ and $E, Z$ isomers) via [4+2]-cycloaddition with singlet oxygen. Endoperoxides 35 and 36 were dihydroxylated and acetal-protected to provide target molecules 37-40. Endoperoxide 37 was further reduced to give target 41 (dibromoallitol) but the reduction of endoperoxide 38 failed to yield pure product $\mathbf{4 2}$. Compounds $\mathbf{3 6}, \mathbf{3 8}$, and $\mathbf{4 0}$ were obtained as racemic mixtures and have been displayed as single enantiomers for clarity. $\mathrm{TPP}=$ tetraphenylporphyrin, $\mathrm{NMO}=N$-methyl morpholine, $N$-oxide; PTSA $=$ para-toluene sulfonic acid; 2,2-DMP = 2,2-Dimethoxypropane; n.p. = no product isolated.

While endoperoxides such as $\mathbf{3 5}$ are generally susceptible to ring-opening (e.g. KornblumDeLaMare rearrangement ${ }^{[18]}$ by basic nucleophiles such as amines, they tolerate a range of 
alkene oxidation reactions well. In addition to the dihydroxylation of alkene $\mathbf{3 5}$ (vide supra) the bromohydrin 47, and epoxides 43 and 44 were synthesised from this common intermediate (Scheme 4). The subsequent reductions of the endoperoxide-linkage were straightforward and gave functionalised diols 45, 46, and triol 48 in excellent yields, illustrating the versatility of the endoperoxide scaffold for generating highly functionalised, pharmacologically relevant molecules in few synthetic steps.

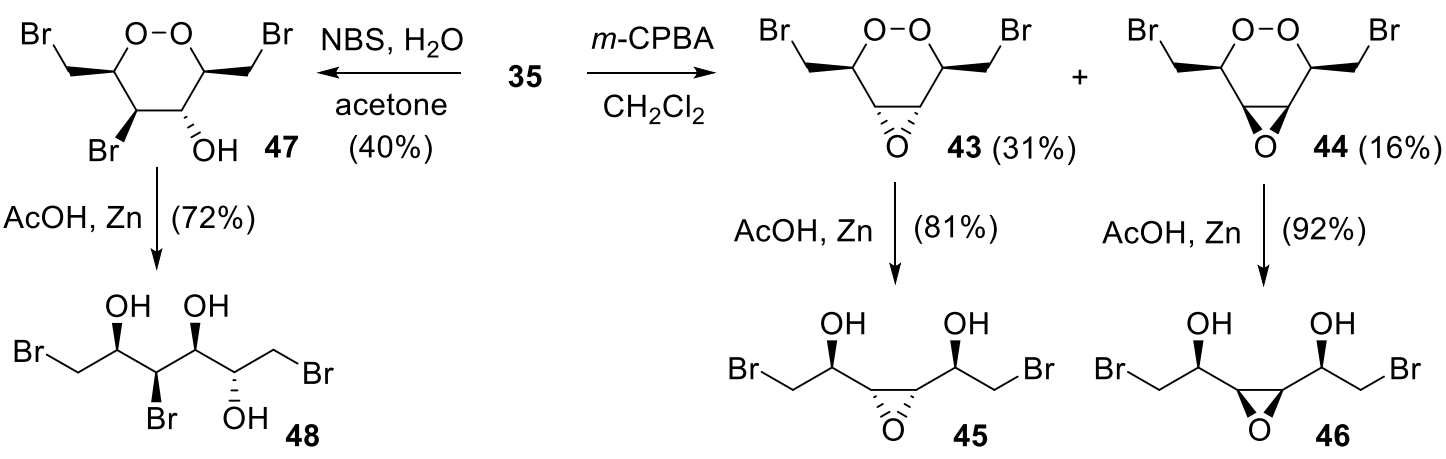

Scheme 4. Epoxidation of alkene 35 yielded epoxides 43 and 44 that were further reduced to target compounds 45 and 46, and bromohydrin synthesis followed by peroxide reduction yielded triol $\mathbf{4 8}$. Compounds $\mathbf{4 7}$ and $\mathbf{4 8}$ were obtained as racemic mixtures but have been displayed as single enantiomers for clarity. NBS $=N$-bromosuccinimide $; m$-CPBA $=$ metachloroperbenzoic acid.

For the pharmacological evaluation of the synthesised endoperoxides and dibromo-polyols we decided to synthesise dibromomannitol (2) and dibromogalactitol (3) as controls. Compound 2 was synthesised in low yield from mannitol 49 using the procedure of CrombezRobert et al. (Scheme 5). ${ }^{[5 a]}$ Interestingly, we failed to synthesise dibromogalactitol 3 under the same conditions, illustrating how elusive these diastereomeric sugars can be. Further attempts at synthesising 3 using aqueous $\mathrm{HBr}$ also failed to give the desired product and we eventually settled for dibromomannitol $\mathbf{2}$ as the control for pharmacological characterisation. 

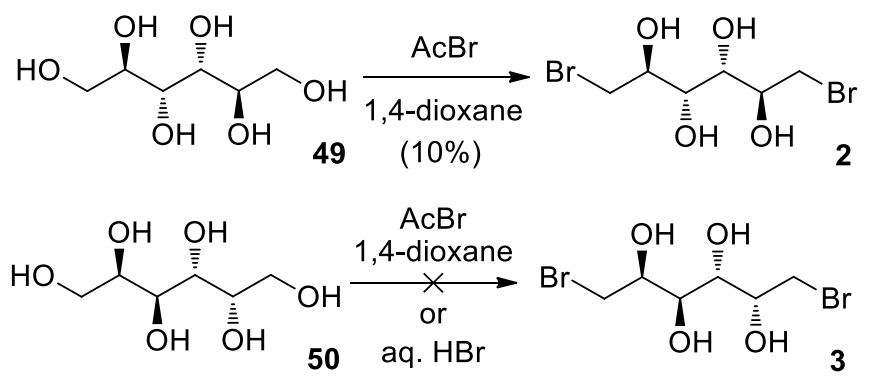

Scheme 5. Synthesis of control compound 2 (dibromomannitol; DBM) from mannitol 49 using acetyl bromide. The conversion of galactitol $\mathbf{5 0}$ to dibromogalactitol (DBG) failed under the same conditions and when using aqueous $\mathrm{HBr}$.

\section{Pharmacology: Chemosensitivity studies}

The response of ARPE-19 non-cancer cells and HCT116 colorectal cancer cells following continuous exposure to test compounds or established anticancer drugs was evaluated under aerobic and hypoxic cell culture conditions at extracellular pH 7.4 (Table 1). Against the HTC116 cell line the response ranged under aerobic conditions from inactive at the highest dose tested ( $\mathrm{IC}_{50}>100 \mu \mathrm{M} ; \mathbf{3 9}$ and $\mathbf{4 1}$ ) to active with the most potent compound (43) having an $\mathrm{IC}_{50}$ of $4.5 \pm 0.6 \mu \mathrm{M}$, although most compounds were found to give a similar response to the reference compound DBM (2). Somewhat surprising, compound 41 which is a stereoisomer of $\mathbf{2}$ was completely inactive. Considering that the corresponding endoperoxide $\mathbf{3 7}$ was active, the lack of activity for $\mathbf{4 1}$ is likely because the compound is unable to reach its target due to unknown factors (e.g. poor cell penetration or compound stability). With respect to selectivity for HTC116 cancer cells over ARPE-19 non-cancer cells, the selectivity index (SI) is here defined as the $\mathrm{IC}_{50}$ values at ARPE-19 cells divided by the $\mathrm{IC}_{50}$ values for HCT116 under aerobic, pHe 7.4 conditions. A handful of compounds $(\mathbf{3 5}, \mathbf{4 3}, \mathbf{4 4})$ showed a modest $\sim 2-3$ fold preference for the cancer cell line while most compounds displayed no selectivity for the HCT116 cells (e.g. 37, 40, 45-48). 
In the context of identifying HAPs we further screened the test compounds against the HCT116 cell line under hypoxic conditions (0.1\% oxygen, Table 1$)$. The hypoxic cytotoxicity ratio (HCR) was calculated as the ratio of $\mathrm{IC}_{50}$ values under aerobic conditions and the $\mathrm{IC}_{50}$ values under hypoxic $(0.1 \%$ oxygen $)$ conditions to illustrate selective toxicity towards cells under hypoxic conditions. Tirapazamine (51) was used as a positive control and an HCR of 9.6 was obtained (Table 1), which is in agreement with that reported in the literature. ${ }^{[19]}$ By contrast, there was no measured increase in cytotoxicity under hypoxic conditions for most test compounds, including the majority of endoperoxides $(\mathbf{3 5}, \mathbf{3 7}, \mathbf{4 3}, \mathbf{4 4}$ and 47). However, endoperoxide 40 demonstrated a statistically significantly greater activity under hypoxic compared to aerobic conditions with an HCR of 2.6. It is interesting to note that the acetal de-protected analogue $\mathbf{3 8}$ only elicit a weak cellular response, which could be caused by poor cell penetration, while the opposite is observed for the structurally very similar pair $\mathbf{3 7}$ and 39. Most noteworthy was the observed cytotoxicity for epoxide $\mathbf{4 6}$ for two reasons: i) with an HCR of 6.8 , epoxide 46 was markedly more cytotoxic under hypoxic conditions despite not being an endoperoxide, and ii) epoxide 46 was more than 50-fold more toxic than its diastereoisomer $\mathbf{4 5}$ to HCT116 cells under hypoxic conditions. Based on the available data it is not possible to rationalise these findings as the activity of the cytotoxic agent is a complex interplay of multiple factors, including compound stability in solution, cell penetration and localisation, activation of prodrug, and interactions with the target etc. It is possible that 46, as an epoxide, causes cytotoxicity through non-specific alkylation or GSH depletion although the striking difference between 46 and its isomer 45 points towards a more specific mechanism that would require further investigations beyond the scope of this study to unravel.

Table 1. Cell toxicity following $96 \mathrm{~h}$ continuous compound exposure under aerobic and hypoxic conditions at pHe 7.4 determined by the MTT assay. ${ }^{[20]}$ Each value represents the 
mean $\mathrm{IC}_{50}(\mu \mathrm{M}) \pm$ standard deviation for at least three independent experiments. For the colorectal cancer cell line HCT116, experiments were conducted under both aerobic and hypoxic conditions ( $0.1 \%$ oxygen). For the non-cancer ARPE-19 cell line, experiments were conducted under aerobic conditions only. Values > 100 indicate that full curves could not be obtained and that the $\mathrm{IC}_{50}$ was higher than the highest concentration tested $(100 \mu \mathrm{M})$. The Hypoxia Cytotoxicity Ratio (HCR) for HCT116 cells is defined as the $\mathrm{IC}_{50}$ values under aerobic conditions divided by the $\mathrm{IC}_{50}$ under hypoxic $(0.1 \%$ oxygen $)$ conditions. Values $>1$ indicate that compounds have selective toxicity towards cells under hypoxic conditions. The selectivity index (SI) is here defined as the $\mathrm{IC}_{50}$ values at $\mathrm{ARPE}-19$ cells divided by the $\mathrm{IC}_{50}$ values for HCT116 under aerobic, pHe 7.4 (values $>1$ indicate greater selectivity for cancer cells as opposed to non-cancer cells). N/A = data not available due to lack of compound availability.

\begin{tabular}{|c|c|c|c|c|c|c|}
\hline \multirow[b]{2}{*}{ Cmpd } & \multirow[b]{2}{*}{ Structure } & \multicolumn{3}{|c|}{ Cytotoxicity $\mathrm{IC}_{50}(\mu \mathrm{M})$} & \multirow[b]{2}{*}{$\begin{array}{c}\text { SI } \\
\text { (pHe 7.4) }\end{array}$} & \multirow[b]{2}{*}{$\begin{array}{c}\text { HCR } \\
\text { (HCT116) }\end{array}$} \\
\hline & & $\begin{array}{l}\text { ARPE-19 } \\
\text { (Aerobic) }\end{array}$ & $\begin{array}{l}\text { HCT116 } \\
\text { (Aerobic) }\end{array}$ & $\begin{array}{c}\text { HCT116 } \\
\text { (Hypoxic) }\end{array}$ & & \\
\hline 2 & & $3.2 \pm 0.9$ & $15.6 \pm 4.3$ & $25.9 \pm 3.5$ & 0.2 & 0.6 \\
\hline 35 & & $17.3 \pm 6.0$ & $7.0 \pm 1.7$ & $13.3 \pm 1.0$ & 2.5 & 0.5 \\
\hline 37 & & $34.2 \pm 5.2$ & $27.7 \pm 10.0$ & $47.5 \pm 3.8$ & 1.2 & 0.6 \\
\hline 38 & HU & N/A & $87.6 \pm 5.4$ & $72.2 \pm 9.3$ & - & 1.2 \\
\hline 39 & & $77.2 \pm 3.8$ & $>100$ & $>100$ & - & - \\
\hline 40 & & $43.0 \pm 5.0$ & $66.4 \pm 8.1$ & $25.9 \pm 3.2$ & 0.6 & 2.613 \\
\hline
\end{tabular}




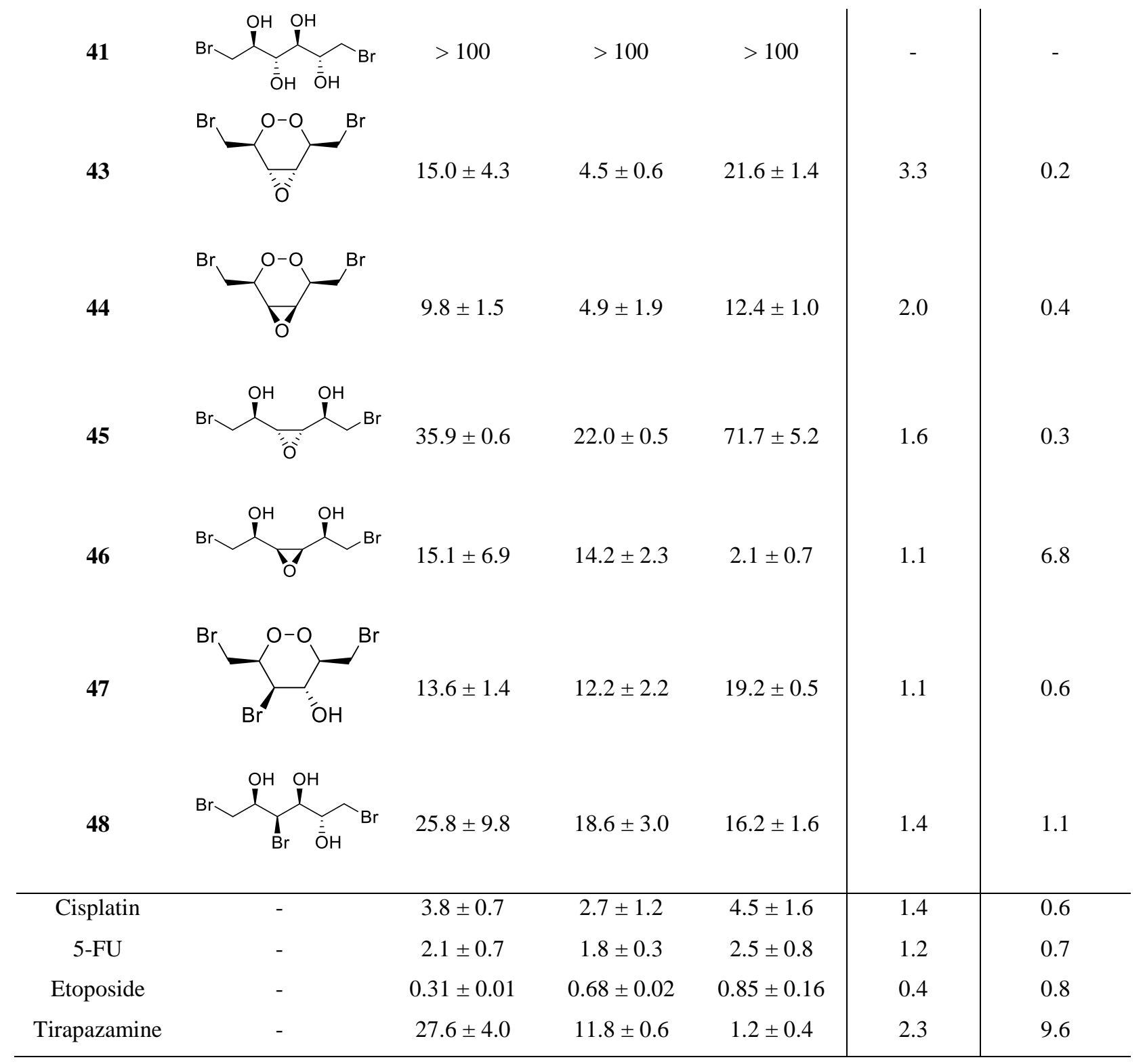

Although our results show that the endoperoxide motif is neither a guarantee of increased compound cytotoxicity under hypoxic conditions (e.g. 39), nor a requirement for such (e.g. 46) we show that it is indeed possible to modify the properties for this class of cytotoxic agents to make them microenvironment-selective, as with endoperoxide $\mathbf{4 0}$. We decided to further evaluate compound $\mathbf{4 0}$ as well as established anti-cancer drugs under mildly acidic conditions (pHe 6.5) to mimic the conditions associated with hypoxic tumours (Figure 4a, Supplementary Table S1). The activity of $\mathbf{4 0}$ was significantly enhanced under aerobic conditions at pHe $6.5\left(\mathrm{IC}_{50}=26.5 \pm 7.0 \mu \mathrm{M}\right)$ when compared to neutral pHe $7.4(66.4 \pm 8.1$ $\mu \mathrm{M})$. When 40 was exposed to the combination of hypoxia and acidic $\mathrm{pHe}$ the potency was 
increased even further $\left(\mathrm{IC}_{50}=16.3 \pm 4.1 \mu \mathrm{M}\right)$ demonstrating that both hypoxia $(0.1 \%$ oxygen) and acidic $\mathrm{pHe}(\mathrm{pH}$ 6.5) generate additive effects when combined. The observed effect could be due to increased lability of the endoperoxide-linkage under reduced pHe resulting in more effective release of the cytotoxic agent or due to acid-catalysed cleavage of the acetal-protection group. The selectivity index for compound $\mathbf{4 0}$ thus increased from 0.6 under aerobic and pHe 7.4 conditions to 2.6 under hypoxia and mildly acidic pHe 6.5 (Figure $4 b)$.

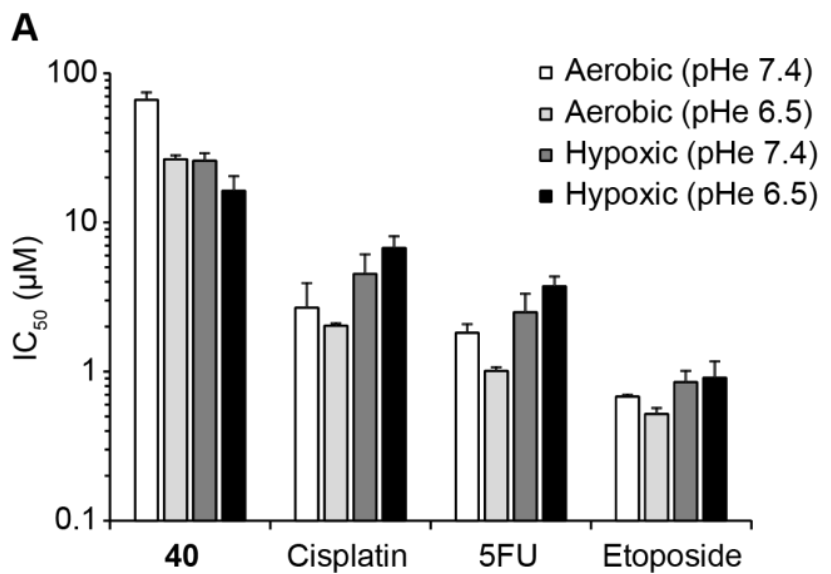

B

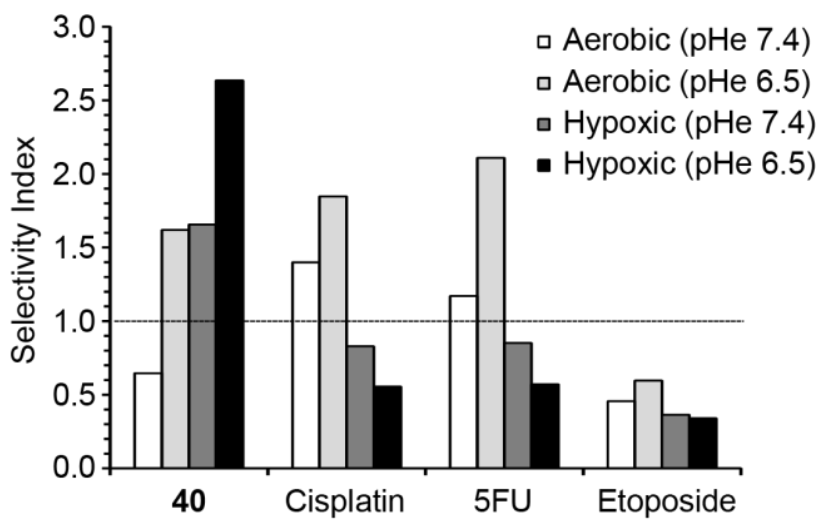

Figure 4. Response of HCT116 cells to compound 40, and the cancer drugs cisplatin, 5fluorouracil (5FU) and etoposide under aerobic and tumour microenvironment conditions. A) $\mathrm{IC}_{50}$ values are presented for different combinations of oxygen tension and extracellular $\mathrm{pH}$ (pHe) including the combination of hypoxia and acidic $\mathrm{pHe}$. Each value represents the mean $\mathrm{IC}_{50} \pm \mathrm{SD}$ for three independent experiments. B) The selectivity index (SI) is defined by the $\mathrm{IC}_{50}$ values at non-cancer ARPE-19 cells (under aerobic and pHe 7.4 conditions, Table 1) 
divided by the $\mathrm{IC}_{50}$ values for cancer HCT116 cells under aerobic, hypoxic, pHe 7.4 or 6.5 conditions respectively (values $>1$ indicate greater selectivity for cancer cells as opposed to non-cancer cells).

Lastly, to shed some light on the mode of action we treated HCT116 cells with endoperoxide $40(20 \mu \mathrm{M})$ under aerobic or hypoxic conditions at pHe 6.5 and 7.4. The cell lysates were then analysed by Western blot to demonstrate that compound $\mathbf{4 0}$ selectively causes phosphorylation of histone $\gamma-\mathrm{H} 2 \mathrm{AX}$, a biomarker for DNA double-strand breaks, ${ }^{[21]}$ under hypoxic conditions at the given concentration (Figure 5). Taken together, these results show that we have developed a dibromo-endoperoxide $\mathbf{4 0}$ derived from the non-selective cytotoxic agent DBM (2) that displays low potency towards the HTC116 cell line under aerobic conditions, but which is triggered under hypoxic conditions to alkylate DNA.

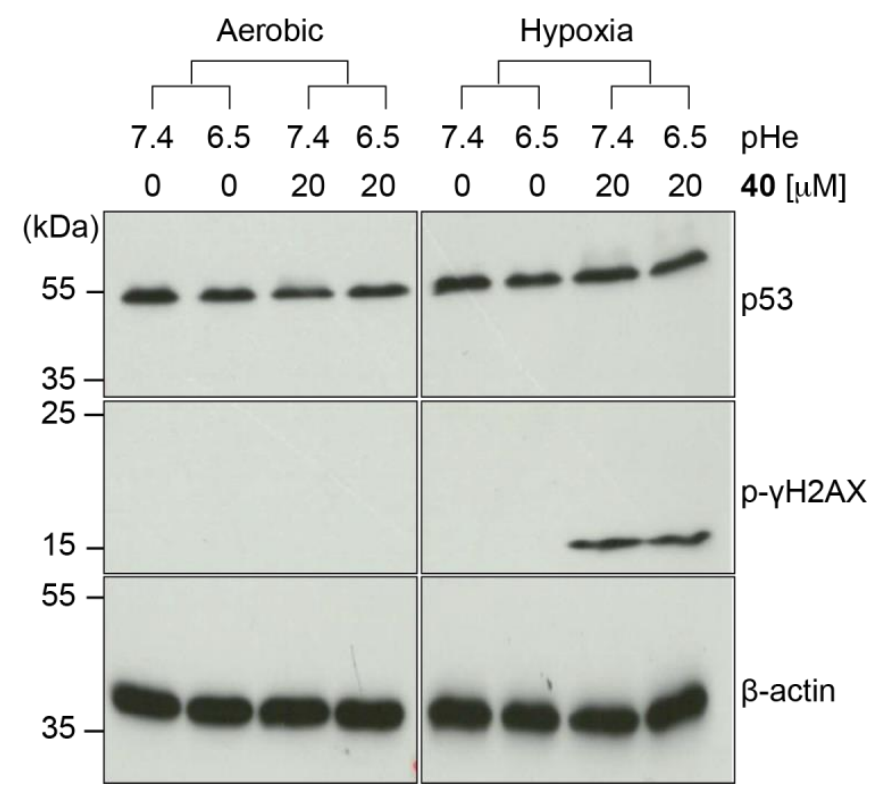

Figure 5. Compound 40 causes DNA breaks under hypoxic conditions. Western blot analysis of p53 and phosphorylated $\gamma$-H2AX induction following the treatment of HCT116 cells with $40(20 \mu \mathrm{M})$ or DMSO for $24 \mathrm{~h}$ under different oxygen tensions and extracellular $\mathrm{pH}$ prior to cell lysis. 


\section{CONCLUSION}

In this study we describe a photochemical synthesis approach that enabled ready access to novel dibromo- and further substituted and functionalised endoperoxides, and we further show that such endoperoxides serve as useful precursors for the synthesis of stereoisomeric analogues (e.g. dibromoallitol 41) of known carbohydrate chemotherapeutics, e.g. DBM (2). The initial pharmacological evaluation revealed that most of these agents show no to modest cytotoxic preference for colorectal HCT116 cancer cells over non-cancer ARPE-19 cells in an MTT assay, with potencies comparable to that of DBM (2). We identified a single endoperoxide 40 that displayed low cytotoxicity and selectivity for cancer cells at extracellular $\mathrm{pH} 7.4$ and under aerobic conditions, but which became more selective under conditions that mimic the tumour microenvironment (e.g. hypoxia and lower $\mathrm{pH}$ ); conditions that favour cleavage of the endoperoxide bond and release of the cytotoxic agent. However, the majority of endoperoxides screened did not elicit the same response pattern and the obtained structure-activity relationship data was inconclusive, highlighting the importance to further investigate the biotransformation, mode of action and physicochemical profiles of these agents to evaluate and optimise compound stability, cell penetration and target engagement. The synthesis strategies reported herein provide the tools required to further explore this important compound class.

\section{ACKNOWLEDGEMENTS}

DSP and HJ acknowledge the Lundbeck Foundation - Natural Sciences (Grant no. R1412013-13342) for financial support. RMP acknowledges funding from the University of Huddersfield (funded PhD studentship). 


\section{REFERENCES}

[1] C. Avendano, J. C. Menendez, DNA Alkylating Agents, In: Medicinal Chemistry of Anticancer Drugs, Amsterdam Elsevier, Amsterdam, 2008, pp. 139-176.

[2] a) N. E. Mischler, R. H. Earhart, B. Carr, D. C. Tormey, Cancer Treat. Rev. 1979, 6, 191-204; b) M. A. Belej, W. M. Troetel, A. J. Weiss, J. E. Stambaugh, R. W. Manthei, Clin. Pharmacol. Ther. 1972, 13, 563-572; c) W. Davis, W. C. J. Ross, Biochem. Pharmacol. 1963, 12, 915-917; d) M. Romanski, A. Pogorzelska, F. K. Glówka, Mol. Pharmaceutics 2019, 16, 2708-2718.

[3] a) E. Institóris, L. Holczinger, D. Bánfi, Krebsforsch. 1974, 82, 101-107; b) E. J. Hidvégi, J. Sebestyén, L. D. Szabó, G. J. Köteles, L. Institoris, Biochem. Pharmacol. 1976, 25, 1705-1710; c) E. Institóris, B. W. Fox, Chem.-Biol. Interact. 1978, 22, 99107; d) E. Institóris, J. Tamás, Biochem. J. 1980, 185, 659-666; e) E. Institóris, Chem.-Biol. Interact. 1981, 35, 207-216.

[4] D. F. Chiuten, M. Rozencweig, D. D. von Hoff, F. M. Muggia, Cancer 1981, 47, 442451.

[5] a) C. Crombez-Robert, M. Benazza, C. Fréchou, G. Demailly, Carbohydr. Res. 1997, 303, 359-365; b) M. Jarman, W. C. J. Ross, Carbohydr. Res. 1969, 9, 139-147; c) E. M. Acton, M. Keyanpour-Rad, J. E. Christensen, H. H. Tong, R. P. Kwok, L. Goodman, Carbohydr. Res. 1972, 22, 477-486.

[6] a) J. M. Ballard, B. E. Stacey, Carbohydr. Res. 1973, 30, 83-89; b) J. A. Hartley, C. C. O’Hare, J. Baumgart, Br. J. Cancer 1999, 79, 264-266; c) E. Oláh, K. Tóth, J. Sugár, L. Hegedüs, S. Somfai-Relle, Cancer Res. 1983, 43, 4530-4536; d) J. Szebeni, B. K., F. Uher, J. Milosevits, K. Paloczi, D. Gaal, G. G. Petranyi, E. Kelemen, Leukemia 1997, 11, 1769-1774. 
[7] a) T. D. Avery, G. Fallon, B. W. Greatrex, S. M. Pyke, D. K. Taylor, E. R. T. Tiekink, J. Org. Chem. 2001, 66, 7955-7966; b) T. D. Avery, B. W. Greatrex, D. K. Taylor, E. R. T. Tiekink, J. Chem. Soc., Perkin Trans. 1 2000, 1319-1321; c) T. D. Avery, N. F. Jenkins, M. C. Kimber, D. W. Lupton, D. K. Taylor, Chem. Commun. 2002, 28-29; d) T. D. Avery, D. K. Taylor, E. R. T. Tiekink, J. Org. Chem. 2000, 65, 5531-5546; e) T. D. Avery, T. D. Haselgrove, D. K. Taylor, E. R. T. Tiekink, T. D. Avery, T. J. Rathbone, Chem. Commun. 1998, 333-334; f) B. W. Greatrex, N. F. Jenkins, D. K. Taylor, E. R. T. Tiekink, J. Org. Chem. 2003, 68, 5205-5210; g) B. W. Greatrex, M. C. Kimber, D. K. Taylor, G. Fallon, E. R. T. Tiekink, J. Org. Chem. 2002, 67, 53075314; h) B. W. Greatrex, M. C. Kimber, D. K. Taylor, E. R. T. Tiekink, J. Org. Chem. 2003, 68, 4239-4246; i) B. W. Greatrex, D. K. Taylor, J. Org. Chem. 2004, 69, 2577 2579; j) B. W. Greatrex, D. K. Taylor, J. Org. Chem. 2005, 70, 470-476; k) B. W. Greatrex, D. K. Taylor, E. R. T. Tiekink, J. Org. Chem. 2004, 69, 2580-2583; 1) M. C. Kimber, D. K. Taylor, Trends Org. Chem. 2001, 9, 53-68; m) M. C. Kimber, D. K. Taylor, J. Org. Chem. 2002, 67, 3142-3144; n) F. N. Palmer, D. K. Taylor, J. Chem. Soc., Perkin Trans. 1 2000, 1323-1325.

[8] a) T. D. Avery, B. W. Greatrex, D. S. Pedersen, D. K. Taylor, E. R. T. Tiekink, J. Org. Chem. 2008, 73, 2633-2640; b) N. J. Stanley, M. R. Hutchinson, T. Kvist, B. Nielsen, J. M. Mathiesen, H. Bräuner-Osborne, T. D. Avery, E. R. T. Tiekink, D. S. Pedersen, R. J. Irvine, A. D. Abell, D. K. Taylor, Bioorg. Med. Chem. 2010, 18, 60896098.

[9] a) S. Domeyer, M. Bjerregaard, H. Johansson, D. S. Pedersen, Beilstein J. Org. Chem. 2017, 13, 644-647; b) D. S. Pedersen, T. V. Robinson, D. K. Taylor, E. R. T. Tiekink, J. Org. Chem. 2009, 74, 4400-4403; c) T. V. Robinson, PhD Thesis, University of Adelaide 2007; d) T. V. Robinson, D. S. Pedersen, D. K. Taylor, E. R. T. Tiekink, J. 
Org. Chem. 2009, 74, 5093-5096; e) T. V. Robinson, D. K. Taylor, E. R. T. Tiekink, J. Org. Chem. 2006, 71, 7236-7244.

[10] R. M. Phillips, Cancer Chemother. Pharmacol. 2016, 77, 441-457.

[11] M. Höckel, P. Vaupel, J. Nat. Cancer Inst. 2001, 93, 266-276.

[12] a) J.-X. Duan, H. Jiao, J. Kaizerman, T. Stanton, J. W. Evans, L. Lan, G. Lorente, M. Banica, D. Jung, J. Wang, H. Ma, X. Li, Z. Yang, R. M. Hoffman, W. S. Ammons, C. P. Hart, M. Matteucci, J. Med. Chem. 2008, 51, 2412-2420; b) A. Warnecke, in Drug Delivery in Oncology: From Basic Research to Cancer Therapy (Eds.: F. Kratz, P. Senter, H. Steinhagen), Wiley-VCH Verlag GmbH \& Co. KGaA, 2012, pp. 553-589.

[13] a) G. O. Ahn, M. Brown, Front. Biosci. 2007, 12, 3483-3501; b) W. A. Denny, Future Oncol. 2010, 6, 419-428; c) R. J. Gillies, R. A. Gatenby, Cancer Metastasis Rev. 2007, 26, 311-317; d) S. R. McKeown, R. L. Cowen, K. J. Williams, Clin. Oncol. 2007, 19, 427-442; e) S. J. Welsh, M. Y. Koh, G. Powis, Sem. Oncol. 2006, 33, 486497; f) K. J. Williams, R. L. Cowen, L. M. Brown, E. C. Chinje, M. Jaffar, I. J. Stratford, Adv. Enzym. Reg. 2004, 44, 93-108; g) A. Bansal, M. Simon, J. Cell Biol. 2018, 217 (7), 2291-2298.

[14] a) F. Kratz, U. Beyer, M. T. Schütte, Crit. Rev. Ther. Drug. Carrier Syst. 1999, 16, 245-288; b) I. F. Tannock, D. Rotin, Cancer Res. 1989, 49, 4373-4384.

[15] X. Zhang, Y. Lin, R. J. Gillies, J. Nucl. Med. 2010, 51, 1167-1170.

[16] G. Schneider, T. Horváth, P. Sohár, Carbohydr. Res. 1977, 56, 43-52.

[17] L. F. Fieser, M. Fieser, Reagents for organic synthesis, Wiley, New York, 1967, pp. 581.

[18] a) M. G. Zagorski, R. G. Salomon, J. Am. Chem. Soc. 1980, 102, 2501-2503; b) N. Kornblum, H. E. DeLaMare, J. Am. Chem. Soc. 1951, 73, 880-881.

[19] J. Su, Y. Gu, F. B. Pruijn, J. B. Smaill, A. V. Patterson, C. P. Guise, W. R. Wilson, J. Biol. Chem. 2013, 288, 37138-37153. 
[20] R. M. Phillips, P. B. Hulbert, M. C. Bibby, N. R. Sleigh, J. A. Double, Br. J. Cancer 1992, 65, 359-364.

[21] L. J. Kuo, L.-X. Yang, In Vivo 2008, 22, 305-309.

\section{Graphical Abstract}

Novel bromo-hexitols based on known DNA-alkylating carbohydrate therapeutics such as dibromomannitol were synthesised by a photochemical approach. One such endoperoxide was identified to have a marked increased activity under hypoxic and low $\mathrm{pH}$ conditions, indicating that endoperoxides may serve as cancer microenvironment-activated prodrugs.

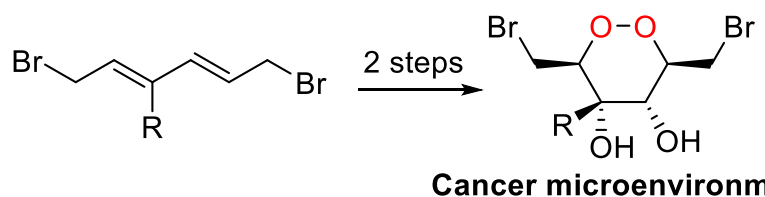

Cancer microenvironmentactivated prodrugs

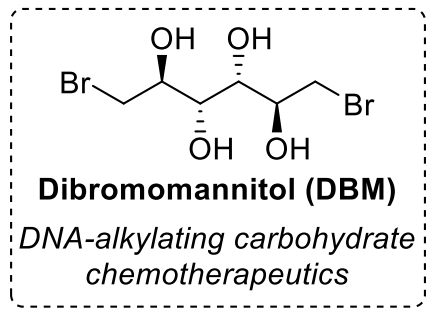

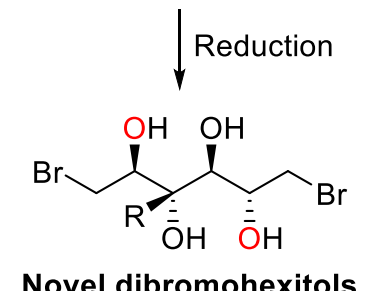

